\title{
Perfil hematológico de bovinos da raça angus criados no município de Londrina/PR
}

Marcela dos Santos Ribeiro, Isadora Naomi Vieira Ogawa, Juliana Joaquim da Silva, Ariane Gerber Aleixo dos Reis, Gustavo Rodrigues Queiroz, Aline Tramontini Zanluchi Queiroz

Universidade Norte do Paraná (UNOPAR) Londrina, PR, Brasil

*Autor correspondente

e-mail: alinetramontinizanluchi@gmail.com

\section{Resumo}

Mudanças fisiológicas importantes ocorrem a partir do nascimento como forma de adaptação à vida extrauterina. O hemograma é uma ferramenta importante para avaliar estas mudanças e alterações decorrentes de enfermidades. 0 objetivo deste estudo foi determinar valores de referência para parâmetros hematológicos em bovinos da raça Angus, assim como comparar os dados em faixas etárias diferentes de bovinos criados na região de Londrina, Paraná. As categorias consideradas foram touros ( $\mathrm{n}=10$ ), vacas $(n=10)$ e bezerros $(n=10)$. Por meio de punção da veia jugular externa, foram colhidas amostras de sangue venoso em tubos com EDTA de dez animais de cada grupo, todos clinicamente sadios. Destas amostras foram feitos os hemogramas de forma manual, sendo as determinações das proteínas plasmáticas totais e do fibrinogênio obtidas por refratometria. A contagem diferencial de leucócitos foi feita em esfregaço corado por corante tipo pan-óptico. Foram obtidos médias e desvios padrões de hematócrito (\%), contagem de hemácias (células x 10\% $\mathrm{mm}^{3}$ ), hemoglobina (g/dL), VCM (fL), CHCM (\%), proteína plasmática total $(\mathrm{g} / \mathrm{dL})$, fibrinogênio $(\mathrm{mg} / \mathrm{dL})$, contagem total de leucócitos $\left(/ \mathrm{mm}^{3}\right)$ e contagem diferencial de leucócitos $\left(/ \mathrm{mm}^{3}\right)$. Para os touros, foram observados valores de hematócrito de $30 \pm 5$,6; contagem de hemácias, 7,7 \pm 0,7; hemoglobina, 13,2 \pm 2,8; VCM, 38,4 \pm 5,4; CHCM, 44,2 \pm 4,2; proteína plasmática total, 7,7 \pm 1,0; fibrinogênio, $420 \pm 166$; contagem total de leucócitos, $16.030 \pm 5.426$; neutrófilos segmentados, $4.064 \pm$ 1.268; neutrófilos bastonetes $59 \pm 127$; linfócitos, $10.803 \pm 3.368$; monócitos, 386,8 \pm 434 ; eosinófilos, 708 \pm 500 ; basófilos, $0 \pm 0$. Para as vacas, foram observados valores de hematócrito de 30,1 $\pm 4,6$; contagem de hemácias, 6,1 \pm 1,2; hemoglobina, 13,1 $\pm 2,3$; VCM, 51,1 \pm 14 ; CHCM, 43,5 $\pm 2,8$; proteína plasmática total, $7,7 \pm 0$,5; fibrinogênio, $360 \pm 158$; contagem total de leucócitos, $13.570 \pm 4.242$; neutrófilos segmentados, $3.509 \pm 1.553$; neutrófilos bastonetes 0,0 \pm 0,0; linfócitos, $7.946 \pm 2.201$; monócitos, $343 \pm 345$; eosinófilos, $1.772 \pm 1.402$; basófilos, $0 \pm 0$. Para os bezerros, foram observados valores de hematócrito de $36,84 \pm 11,0$; 
contagem de hemácias, 7,41 \pm 2,42; hemoglobina, 13,32 $\pm 3,67$; VCM, 50,67 \pm 8,96; CHCM, 36,99 \pm 5,87; proteína plasmática total, $6,27 \pm 0,39$; fibrinogênio, $510 \pm 152$; contagem total de leucócitos, $11.150 \pm$ 4.289; neutrófilos segmentados, $1.992 \pm 1.309$; neutrófilos bastonetes $51 \pm 91$; linfócitos, $6.924 \pm 4.275$; monócitos, $1.873 \pm 4.083$; eosinófilos, $328 \pm 948$; basófilos, $0 \pm 0$. Os resultados obtidos neste estudo podem servir como valores de referência para bovinos da raça Angus criados no norte do Paraná, em condições semelhantes de clima e de manejo nutricional. 